\title{
Sistem Pakar Deteksi Penyakit Refraksi Mata Dengan Metode Teorema Bayes Berbasis Web
}

\author{
Rizal Rachman ${ }^{1}$, Sera Moritami ${ }^{2}$ \\ ${ }^{1}$ STMIK Nusa Mandiri \\ e-mail: rizalkhaizuran@gmail.com \\ ${ }^{2}$ Universitas ARS \\ e-mail: seramoritami@gmail.com
}

\begin{abstract}
Abstrak
Masalah gangguan penglihatan di Indonesia, sebagian besar disebabkan oleh kurangnya pengetahuan mengenai penyakit mata dan sering menganggap enteng kasus penyakit mata, khususnya refraksi. Gangguan penglihatan di Indonesia khususnya Jawa Barat telah menjadi masalah kesehatan masyarakat, oleh sebab itu, perlu upaya penanggulangan yang terpadu dengan pelibatan semua sektor termasuk profesi di dalamnya, sehingga di masa mendatang tidak lagi menjadi masalah kesehatan masyarakat. Saat ini,sekitar 314 juta orang di dunia mengalami penglihatan lemah dan 45 juta diantaranya merupakan kasus kebutaan. terlambatnya kesadaran penderita, dan mahalnya biaya untuk konsultasi membuat para penderita enggan untuk ke dokter spesialis. Sistem pakar deteksi penyakit refraksi mata ini diharapkan dapat memberikan pengetahuan mengenai diagnosa penyakit refraksi mata pada penderita, memberikan sarana berupa media konsultasi mengenai penyakit pada refraksi mata serta meminimalisir biaya konsultasi ke dokter ahli. Sistem pakar merupakan bagian dari kecerdasan buatan yang meniru penalaran manusia. Pemanfaatan teknologi memudahkan manusia untuk mengakses informasi tanpa terbatas ruang dan waktu. Metode Teorema Bayes adalah metode yang menerapkan aturan yang dihubungkan dengan nilai probabilitas atau kemungkinan untuk menghasilkan suatu keputusan dan informasi yang tepat berdasarkan penyebab yang terjadi. Hasil dari penelitian ini yaitu aplikasi sistem pakar yang dapat memberikan pengetahuan mengenai diagnosa penyakit refraksi mata, menjadi media untuk berkonsultasi mengenai penyakit bagi penderita.
\end{abstract}

Kata Kunci: Refraksi Mata, Sistem Pakar, Teorema Bayes

\begin{abstract}
Visual impairment problem in Indonesia is mainly due to the lack of knowledge about eye diseases and often underestimate eye disease cases, especially refractive. Visual impairment in Indonesia, especially West Java, have become a health problem of the society, therefore, an integrated treatment effort is needed with the involvement of all sectors including the profession in them, so in the future it will no longer be a health problem of the society. At the present time, around 314 million people in the world experience weak vision and 45 million of them are blindness cases. Late awareness of the patient, and the high cost for consultation make patients reluctant to go to a specialist doctor. This expert system for refractive disorder detection is expected to provide knowledge about the diagnosis of refractive disorder in patients, providing a means in the form of consultation media about refractive disorder and minimizing the cost of consulting a specialist doctor. Expert system is a part of artificial intelligence that mimics human reasoning. The use of technology makes it easy for humans to access information without limited space and time. The Bayes Theorem Method is a method that applies rules that are associated with probability values or the possibility to generate a decision and information that is accurate based on the causes that occur. The result of this study is the expert systems application that can provide knowledge about the diagnosis of refractive disorder, to be the media to consult about the diseases for the patients.
\end{abstract}

Keywords: Refractive, Expert System, Bayes Theorem 


\section{Pendahuluan}

Hasil Survei Kebutaan Rapid Assesment Of Avoidable Blindness (RAAB) yang dilakukan Perhimpunan Dokter Ahli Mata Indonesia (PERDAMI) dan Badan Litbangkes, tahun 2014-2016 di 15 Provinsi menunjukkan prevelensi kebutaan sebesar $3 \%$ dan penyebab utama kebutaan di Indonesia adalah katarak (70.80\%), sedangkan penyebab utama gangguan penglihatan adalah kelainan refraksi (10.15\%). Survei tersebut dilakukan pada penduduk diatas usia 50 tahun, sebnayak 15 provinsi itu sudah mencakup 65\% orang Indonesia. Sementara untuk sekali survey dibutuhkan dana sekitar 15 juta (Depkes, 2017).

Masalah gangguan penglihatan di Indonesia khususnya Jawa Barat telah menjadi masalah kesehatan masyarakat oleh sebab itu, perlu upaya penanggulangan yang terbadu dengan pelibatan semua sektor termasuk profesi didalamnya, sehingga di masa mendatang tidak lai menjadi masalah kesehatan masyarakat. Saat ini, sekitar 314 juta orang di dunia mengalami penglihatan lemah dan 45 juta diantaranya merupakan kasus kebutaan. Dengan rincian $87 \%$ insiden penglihatan lemah tersebut terjadi di negara berkembang dan sepertiganya terjadi di Asia Tenggara (Suhendar, 2017).

Kelainan refraksi mata merupakan gangguan umum pada penglihatan, yakni kondisi dimana cahaya yang masuk ke dalam mata tidak dapat difokuskan dengan jelas. Hal ini membuat bayangan benda terlihat buram atau tidak tajam. Penyebabnya bisa karena panjang bola mata terlalu panjang atau bahkan terlalu pendek, perubahan bentuk kornea, dan penuaan lensa mata (Marianti, 2017).

Gangguan refraksi di antaranya myopia yaitu bayangan dari benda yang terletak jauh berfokus di depan retina pada mata yang tidak berakomodasi. Hipermetropi atau Hiperopia atau rabun dekat adalah kelainan refraksi mata di mana bayangan dari sinar yang masuk ke mata jatuh di belakang retina. Serta Astigmatisme adalah gangguan penglihatan yang di akibatkan kelainan pada kelengkungan lensa atau kornea yang berakibat pandangan terdistorsi atau kabut (Zoraya, 2018).

Sistem pakar merupakan bagian dari kecerdasan buatan yang meniru penalaran manusia. Pemanfaatan teknologi memudahkan manusia untuk mengakses informasi tanpa terbatas ruang dan waktu (Sihotang, Panggabean, \& Zebua, 2018).

Salah satu alternatif penggunaan sistem pakar untuk diagnosis penyakit refraksi mata yaitu dengan menggunakan metode teorema bayes. Dengan adanya sistem ini diharapkan dapat memberikan pengetahuan mengenai diagnosa penyakit refraksi mata dan menjadi media untuk berkonsultasi mengenai penyakit refraksi mata.

Penelitian pertama oleh (Setiawan \& Ratnasari, 2014) dari jurnal penelitian dengan judul "Sistem Pakar Diagnosis Penyakit Mata Menggunakan NaiveBayes Classifier" yang berbasis dekstop. Hasilnya, sistem mampu memberikan hasil kemungkinan penyakit yang dialami, presentase keyakinan, tapi sistem ini juga membutuhkan data yang cukup besar untuk mengetahui keakuratan dan kehandalan sistem ini.

Penelitian kedua oleh (Purwanto \& Atina, 2017) dari jurnal penelitian dengan judul "Sistem Pakar Deteksi Dini Gangguan Mata dan Syaraf Akibat Penggunaan Smartphone" dengan menggunakan metode Certainty Factor yang berbasis dekstop. Hasilnya, sistem ini dapat mengidentifikasi masalah kesehatan berdasarkan gejalagejala yang tampak pada pengguna smartphone menggunakan metode certainty factor untuk menghitung presentase kepastian sehingga pengguna dapat mengetahui berapa tingkat kepastian penyakit yang dialami.

$$
\text { Penelitian ketiga oleh }
$$

(Qamaruzzaman \& Sam'ani, 2016) dari jurnal penelitian dengan judul "Sistem Pakar Untuk Mendiagnosa Penyakit Mata Pada Manusia Menggunakan Teorema Bayes" yang berbasis dekstop. Hasilnya, sistem ini menggunakan metode inferensi forward chaining dan backward chaining untuk menentukan kesimpulan hasil diagnosa dan dapat memecahkan masalah untuk mengetahui jenis penyakit dan nilai probabilitasnya, penyebab serta solusi penanganan.

Penelitian keempat oleh (Permana \& Wijaya, 2017) dari jurnal penelitian dengan judul "Sistem Pakar Diagnosa Penyakit Mata Menggunakan Metode Certainty Factor Berbasis Android". Hasilnya, sistem ini memiliki presentasi keakuratan yang 
lumayan besar dan dapat mendiagnosa penyakit dengan tingkat kepercayaan yang telah ditentukan oleh pakar terhadap gejala yang mempengaruhi probabilitas terjadinya suatu penyakit mata.

Penelitian kelima oleh (Rahmatullah, Purnia, \& Suryanto, 2018) dari jurnal penelitian yang berjudul "Sistem Pakar Untuk Mendiagnosa Penyakit Mata Dengan Metode Forward Chaining" yang berbasis web. Hasilnya adalah sistem dapat mendiagnosa penyakit mata yang sering terjadi, dengan berbasis web online membuat masyarakat lebih mudah mendiagnosa penyakit yang di derita sebelum mengambil tindakan lebih lanjut. Aplikasi ini juga menjadi sarana untuk menyimpan pengetahuan mengenai penyakit mata pada manusia.

Penelitian keenam oleh (Fathimah, Suryatiningsih, \& KomalaSari, 2015) dari jurnal penelitian yang berjudul "Aplikasi Diagnosis Kelainan Refraksi Mata Dan Tips Perawatan Mata Dengan Metode Forward Chaining Berbasis Web". Hasilnya, aplikasi ini dapat melakukan pemeriksaan kelainan refraksi dan dapat mengetahui hasil diagnosis, tips perawatan mata yang sesuai dengan kelainan yang dialami, dan mengetahui solusi jenis lensa yang sesuai dengan kelainan yang dialami.

Penelitian ketujuh oleh (Sihotang, Panggabean, \& Zebua, 2018) dari jurnal penelitian dengan judul "Sistem Pakar Mendiagnosa Penyakit Herpes Zoster Dengan Menggunakan Metode Teorema Bayes" yang berbasis dekstop. Hasilnya, sistem ini dapat mendiagnosa penyakit herpes zoster, berdasarkan gejala yang ditemukan pada tipe penyakit mampu memberikan informasi untuk solusi pengobatan penyakit.

Penelitian kedelapan oleh (Syahrizal \& Haryati, 2018) dari jurnal penelitian dengan judul "Perancangan Aplikasi Sistem Pakar Deteksi Kerusakan Mesin Alat Berat (Beko) Dengan Menerapkan Metode Teorema Bayes" yang berbasis dekstop. Hasilnya, sistem ini dapat mengidentifikasi kerusakan mesin alat berat(beko) atau excavator dengan mengetahui gejala kerusakan yang dimiliki untuk memudahkan pengguna.

Penelitian kesembilan oleh (Umayah, Astuti, \& Maharani, 2018) dari jurnal penelitian yang berjudul "Sistem Pakar Untuk Mendiagnosa Penyakit Pada Tanaman Kakao Menggunakan Metode
Teorema Bayes". Hasilnya, sistem ini dapat mendiagnosa dan dapat memberikan solusi untuk penanggulangan penyakit tanaman kakao serta dapat membantu pekerjaan seorang pakar, dan didapatkan persentase perhitungan yang akurat.

Penelitian kesepuluh oleh (Ramadhan, 2018) dari jurnal penelitian dengan judul "Sistem Pakar Pendiagnosaan Dermatitis Imun Menggunakan Teorema Bayes" yang berbasis web. Hasilnya, sistem dapat mengidentifikasi gejala dan mengetahui tingkat probablitas, sistem diimplementasikan sebagai sarana konsultasi dan pengambilan diagnosa awal dalam melakukan pengidentifikasian terhadap penyakit.

\section{Metode Penelitian}

Metode penelitian yang digunakan dalam penelitian ini adalah metode analisis deskriptif yaitu suatu metode yang bertujuan untuk mendapatkan gambaran yang jelas tentang hal-hal yang diperlukan melalui beberapa tahapan.

\section{Metode Pengumpulan Data}

Teknik pengumpulan data merupakan cara-cara yang dilakukan untuk memperoleh data dan keterangan-keterangan yang diperlukan dalam penelitian (Sugiyono, 2017).

Maka dari itu penulis menggunakan metode pengumpulan data sebagai berikut :

1. Observasi

Penulis melakukan riset langsung dengan mendatangi lokasi kediaman dokter (pakar).

2. Wawancara

Dalam penulisan ini, untuk mendapatkan informasi yang lengkap dan akurat kebenarannya, maka penulis melakukan wawancara langsung dengan dokter(pakar).

3. Studi Pustaka

Metode pengumpulan data dengan cara pengumpulan informasi dari artikel, buku, literatur atau tulisan pada situs internet atau media lainnya. Studi pustaka yang peneliti lakukan ditujukan untuk mengetahui secara rinci mengenai gejala pada refraksi mata, penyebab penyakit refraksi mata dan pemrograman web. 


\section{Metode Pengembangan Pakar}

Teorema Bayes adalah cara untuk mengetahui probabilitas bersyarat. Probabilitas bersyarat adalah probabilitas dari suatu peristiwa yang terjadi, mengingat bahwa itu memiliki beberapa hubungan dengan satu atau lebih peristiwa lainnya. Teorema Bayes memiliki bentuk umum sebagai berikut (Kusrini \& Luthfi, 2009) :

$$
P(H \mid X)=\frac{P(X \mid H) P(H)}{P(X)}
$$

Dalam hal ini:

$\mathrm{X}=$ data dengan class yang belum diketahui

$\mathrm{H}=$ hipotesis data $\mathrm{X}$ merupakan suatu class spesifik

$\mathrm{P}(\mathrm{HIX})=$ probabilitas hipotesis $\mathrm{H}$ berdasar kondisi $X$

$\mathrm{P}(\mathrm{H}) \quad=$ probabilitas hipotesis $\mathrm{H}$

$\mathrm{P}(\mathrm{X} \mid \mathrm{H})=$ Probabilitas $\mathrm{X}$ berdasarkan kondisi pada hipotesis $\mathrm{H}$

$\mathrm{P}(\mathrm{X}) \quad=$ Probabilitas dari $\mathrm{X}$

\section{Algoritma Sistem Pakar}

Algoritma yang akan diimplementasikan oleh penulis pada program sistem pakar ini yaitu di mulai dari proses tampilkan pilihan gejala dan pilih gejala kemudian input dengan memilih gejala kemudian tampil suatu kemungkinan yang akan menghasilkan beberapa kemungkinan jawaban atau pilihan dan diakhiri dengan hasil diagnosa berikut dengan prosentasenya. Untuk keterangan lebih jelas bisa dilihat pada Gambar 1 .

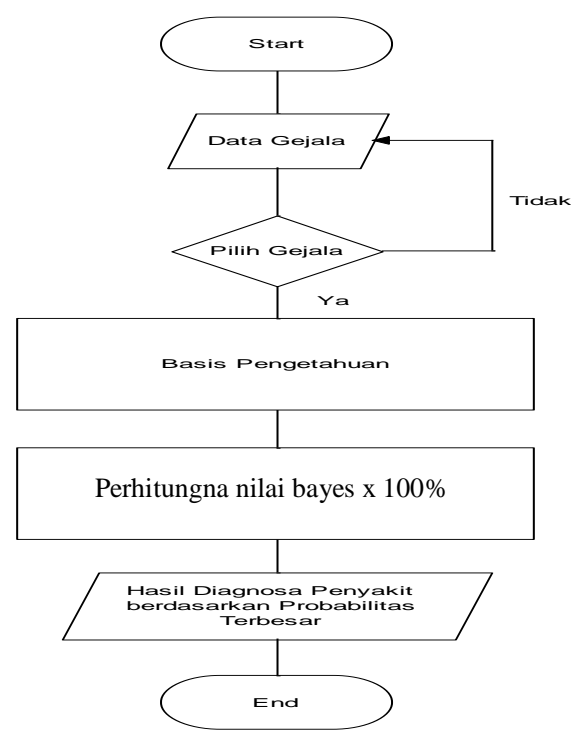

Gambar 1. Algoritma Sistem Pakar

\section{Hasil dan Pembahasan}

Dalam membangun sebuah aplikasi sistem pakar diagnosis penyakit pada ibu hamil, penulis menentukan beberapa tabel yang dibutuhkan aplikasi adapun tabel yang penulis buat, diantaranya :

Tabel 1. Daftar Penyakit

\begin{tabular}{|c|c|}
\hline Kode & Nama penyakit \\
\hline P01 & Miopia \\
\hline P02 & Hipermetropia \\
\hline P03 & Astigmatisma \\
\hline P04 & Presbiopi \\
\hline
\end{tabular}

Tabel 2. Daftar Gejala

\begin{tabular}{|l|l|}
\hline Kode & \multicolumn{1}{|c|}{ Nama Gejala } \\
\hline G01 & Pandangan kabur saat melihat objek \\
\hline G02 & Sering menyipitkan mata \\
\hline G03 & Sakit kepala \\
\hline G04 & Mata lelah \\
\hline G05 & Sering menggosok mata \\
\hline G06 & $\begin{array}{l}\text { Frekuensi mengedipkan mata yang } \\
\text { berlebihan }\end{array}$ \\
\hline G07 & Melihat objek jauh terlihat jelas \\
\hline G08 & Melihat objek dekat terlihat buram \\
\hline G09 & $\begin{array}{l}\text { Mengerlingkan mata untuk melihat } \\
\text { objek jelas }\end{array}$ \\
\hline G10 & Kesulitan membaca \\
\hline G11 & Mata terasa panas dan gatal \\
\hline G12 & Distorsi penglihatan \\
\hline G13 & Pandangan samar \\
\hline G14 & Sulit melihat saat malam hari \\
\hline G15 & Mata sering tegang dan mudah lelah \\
\hline G16 & Sensitif pada sorotan cahaya \\
\hline
\end{tabular}




\begin{tabular}{|l|l|}
\hline G17 & $\begin{array}{l}\text { Kesulitan membedakan warna yang } \\
\text { mirip }\end{array}$ \\
\hline G18 & Penglihatan ganda \\
\hline G19 & Membutuhkan penerangan lebih \\
\hline
\end{tabular}

\begin{tabular}{|l|l|}
\hline & saat membaca \\
\hline G20 & Sulit membaca huruf berukuran kecil \\
\hline
\end{tabular}

Adapun tabel keputusan pakar dibuat untuk menghubungkan tabel penyakit dengan tabel gejala, keterangan bisa dilihat di Tabel3.

Tabel 3. Tabel Keputusan Pakar

\begin{tabular}{|l|l|l|l|l|}
\hline Kode & P01 & P02 & P03 & P04 \\
\hline G01 & $\mathrm{X}$ & & & $\mathrm{X}$ \\
\hline G02 & & $\mathrm{X}$ & $\mathrm{X}$ & $\mathrm{X}$ \\
\hline G03 & $\mathrm{X}$ & & & \\
\hline G04 & $\mathrm{X}$ & & & \\
\hline G05 & $\mathrm{X}$ & & & \\
\hline G06 & & $\mathrm{X}$ & $\mathrm{X}$ & \\
\hline G07 & & $\mathrm{X}$ & & \\
\hline G08 & & $\mathrm{X}$ & & \\
\hline G09 & & $\mathrm{X}$ & & \\
\hline G10 & & $\mathrm{X}$ & $\mathrm{X}$ & \\
\hline G11 & & & $\mathrm{X}$ & \\
\hline G12 & & & $\mathrm{X}$ & \\
\hline G13 & & & $\mathrm{X}$ & \\
\hline G14 & & & & \\
\hline G15 & & & & \\
\hline G16 & & & & \\
\hline G17 & & & & \\
\hline G18 & & & & \\
\hline G19 & & & & \\
\hline G20 & & & \\
\hline
\end{tabular}

Dalam sistem pakar menentukan jenis penyakit refraksi mata ini terdapat perhitungan menggunakan Teorema Bayes. Nilai probabilitas penyakit didapatkan dari 1 dibagi Banyaknya jumlah penyakit yang ada. Sedangkan probabilitas gejala didapatkan dari 1 / jumlah gejala tertentu yang ada diseluruh penyakit.

Misalkan dalam menentukan penyakit, refraksi mata memilih beberapa gejala diantaranya: 
1. Pandangan kabur saat melihat objek (G01)

2. Sering menyipitkan mata (G02)

3. Sakit kepala (G035) .

Berikut contoh perhitungan Teorema

Bayes:

Menghitung total bayes pada Probabilitas

Penyakit pada penyakit Presbiopi P04

1. $P(P 04 \mid G 01)$

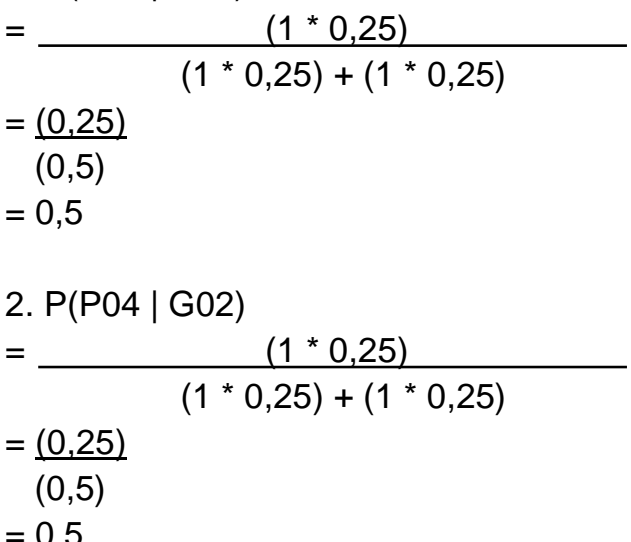

3. $P(P 04 \mid G 03)$

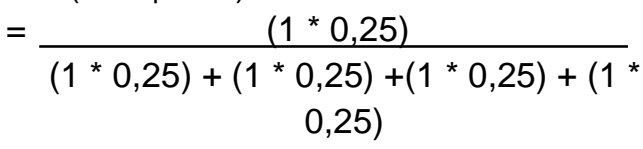

$=\underline{(0,25)}$

(1)

$=0,25$

Total Bayes $1(\mathrm{P} 04)=0.5+0,5+0,25=$ 1,25

Menghitung total bayes pada Probabilitas Penyakit pada Astigmatisma P03

1. $P(P 03 \mid G 01)$

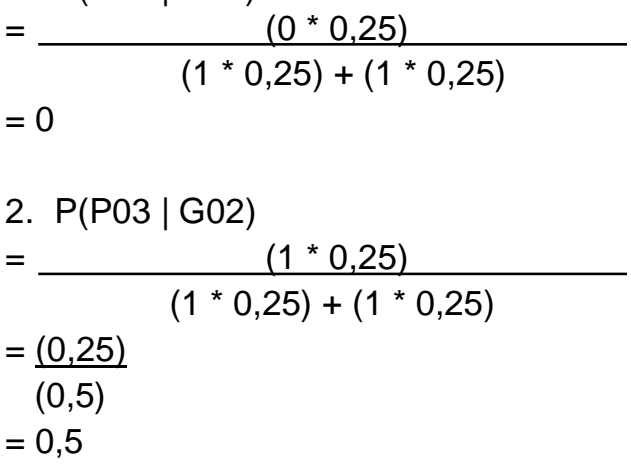

3. $\mathrm{P}(\mathrm{P} 03 \mid \mathrm{G} 03)$

$=\frac{(1 * 0,25)}{(1 * 0,25)+\left(1^{*} 0,25\right)+\left(1{ }^{*} 0,25\right)+(1 * 0,25)}$ $=\underline{(0,25)}$

$(1)$

$=0,25$

Total Bayes $2(\mathrm{P} 03)=0+0,5+0,25=0,75$

Menghitung total bayes pada Probabilitas Penyakit pada Miopia P01

1. $P(P 01 \mid G 01)$

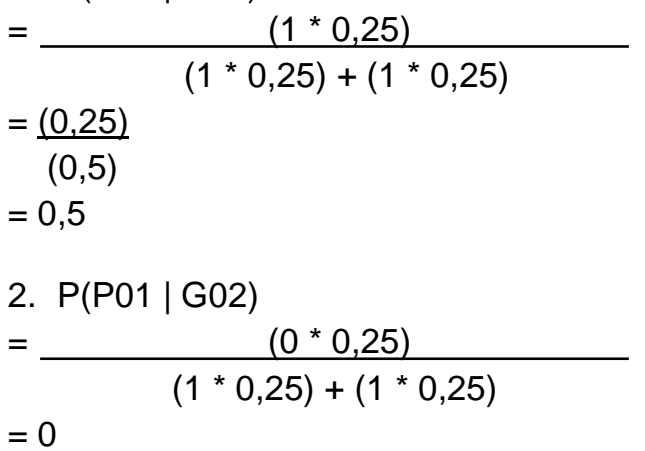

3. $P(P 01 \mid G 03)$

$=\frac{\left(1^{*} 0,25\right)}{(1 * 0,25)+\left(1^{*} 0,25\right)+\left(1^{*} 0,25\right)+(1 * 0,25)}$ $=\underline{(0,25)}$

$=0,25$

Total Bayes $3(P 01)=0,5+0+0,25=0,75$

Hasil Akhir Bayes $=$ Bayes $1+$ Bayes $2+$ Bayes 3

Hasil Akhir Bayes $=1,25+0,75+0,75$

Hasil Akhir Bayes $=2.75$

$$
\begin{aligned}
& P(P 04)=\frac{1,25}{2,75} \times 100 \% \\
& =0.45 \times 100 \%=45 \% \\
& P(P 03)=\frac{0,75}{2,75} \times 100 \% \\
& =0.27 \times 100 \%=27 \% \\
& P(P 01)=\frac{0,75}{2,75} \times 100 \% \\
& =0.27 \times 100 \%=27 \%
\end{aligned}
$$

Dari hasil diatas nilai penyakit tertinggi adalah hasil diagnosa penyakit refraksi yang sedang dialami penderita yaitu, Presbiopi atau P04 dengan prosentase $45 \%$.

\section{Analisa Kebutuhan Software}


Di dalam analisa kebutuhan software ini akan dijelaskan tahapan perancangan sistem yang akan dibuat untuk mempersiapkan proses implementasi sistem dan untuk menggambarkan secara jelas proses-proses yang diinginkan di dalam membangun perangkat lunak.

\section{Use Case Diagram}

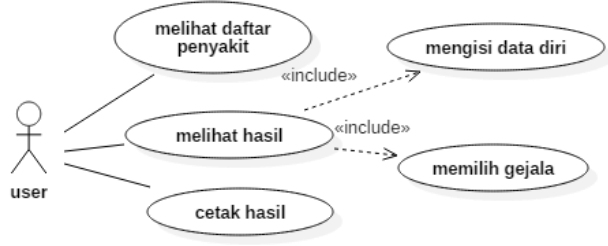

Gambar 2. Use Case Diagram

2. Activity Diagram Halaman Konsultasi Cek Gejala \& Isi Data Diri

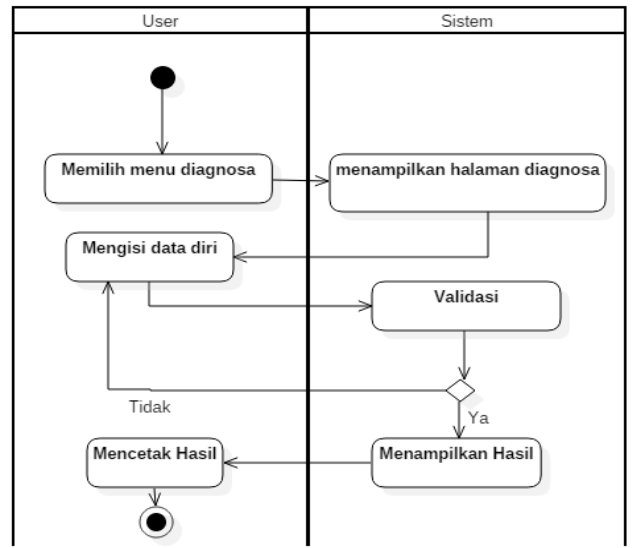

Gambar 3. Activity Diagram Halaman Konsultasi Cek Gejala \& Isi Data Diri

3. Activity Diagram Halaman Login Admin

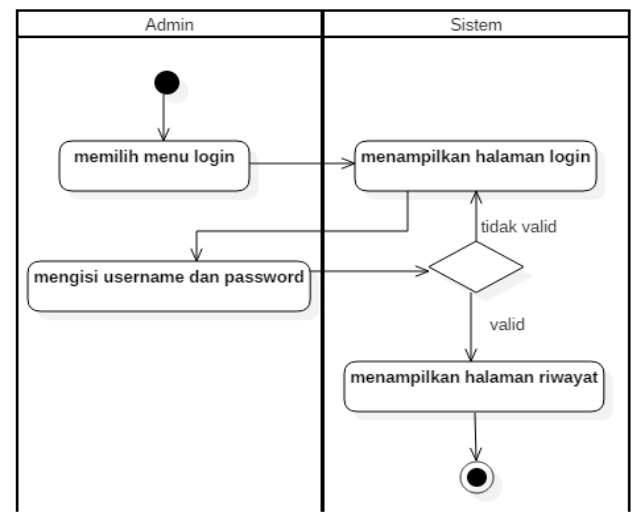

Gambar 4. Activity Diagram Halaman Login Admin
4. Activity Diagram Halaman Riwayat Diagnosa

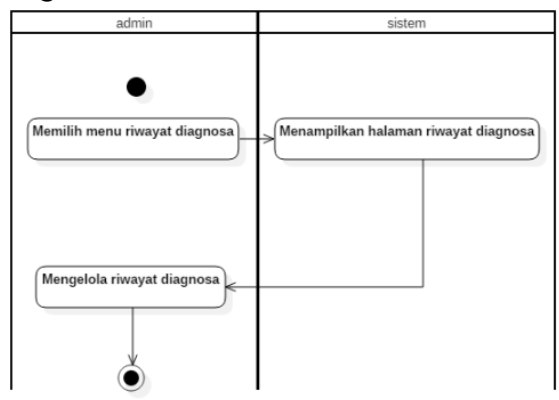

Gambar 5. Activity Diagram Halaman Riwayat Diagnosa

\section{User Interface}

Berikut merupakan tampilan antarmuka dari sistem pakar deteksi penyakit refraksi mata dari tampilan antarmuka untuk pengguna

1. Halaman Utama dan Informasi Penyakit

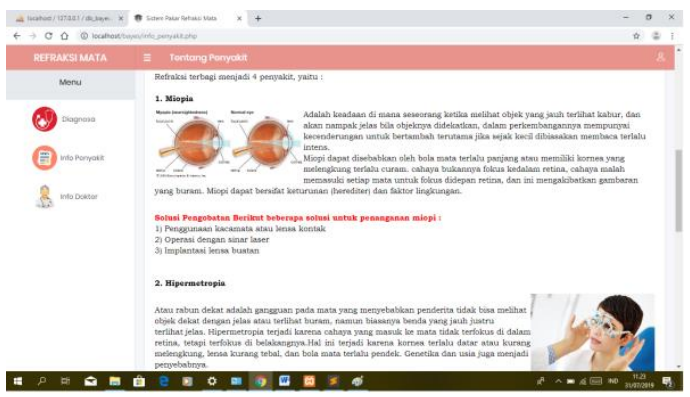

Gambar 6. Halaman Utama dan Informasi Penyakit

2. Halaman Diagnosa Form Isi Data Diri

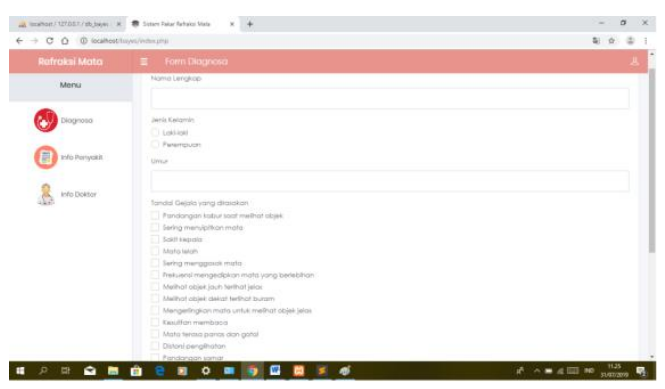

Gambar 7. Halaman Diagnosa Form Isi Data Diri

3. Halaman Hasil dan Cetak Hasil 


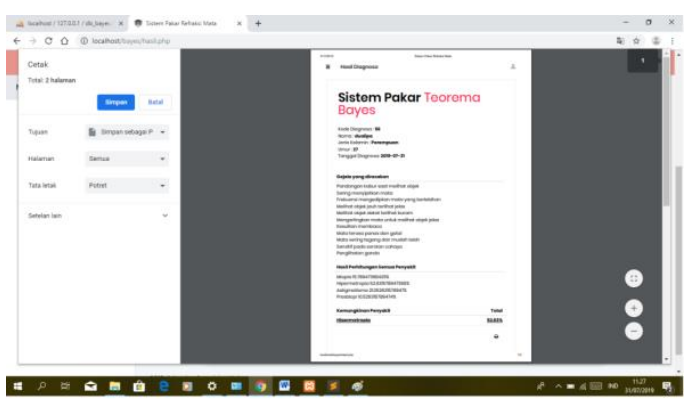

Gambar 8. Halaman Hasil dan Cetak Hasil

4. Halaman Login Admin

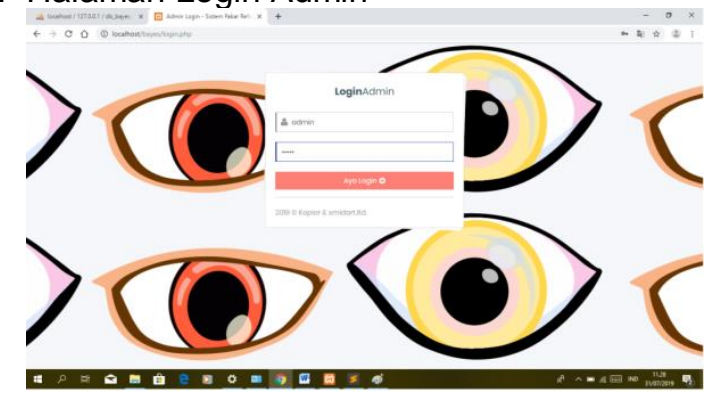

Gambar 9. Halaman Login Admin

5. Halaman Awal Admin

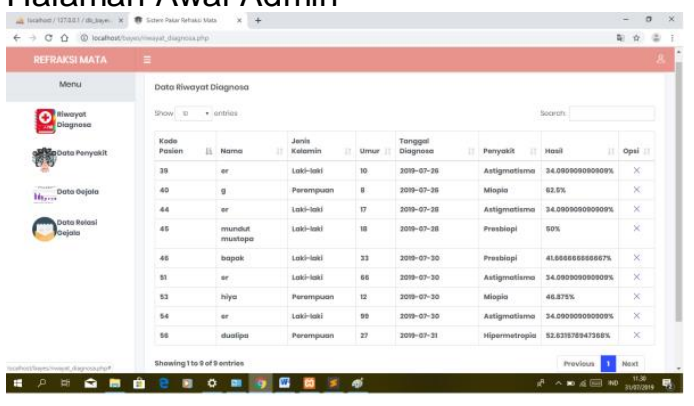

Gambar 10. Halaman Awal Admin

\section{Kesimpulan}

Beberapa kesimpulan dari sistem pakar deteksi penyakit refraksi mata sebagai berikut:

1. Aplikasi sistem pakar ini dapat memberikan pengetahuan mengenai diagnosa penyakit refraksi mata terhadap penderita.

2. Aplikasi sistem pakar ini dapat menjadi media untuk berkonsultasi mengenai penyakit refraksi mata.

3. Aplikasi sistem pakar ini bentuk penerapan metode teorema bayes dalam mendiagnosa penyakit refraksi mata dan dapat membantu mengurangi banyaknya biaya konsultasi ke dokter ahli.

\section{Referensi}

Depkes. (2017). Jakarta: Kementrian Kesehatan Republik Indonesia.

Fathimah, S., Suryatiningsih, \& KomalaSari, S. (2015). Aplikasi Diagnosis Kelainan Refraksi Mata Dan Tips Perawatan Mata Dengan Metode Forward Chaining Berbasis Web. JURNAL INFOTEL, 3(1).

Marianti. (2017). Beragam Kelainan Refraksi Mata yang Perlu Anda Ketahui. Jakarta: www.alodokter.com.

Permana, Y., \& Wijaya, I. G. (2017). Sistem Pakar Diagnosa Penyakit Mata Menggunakan Metode Certainty Factor Berbasis Android. JCOSINE, Vol. 1, No. 1, .

Purwanto, E., \& Atina, V. D. (2017). Sistem Pakar Deteksi Dini Gangguan Mata dan Syaraf Akibat Penggunaan Smartphone" dengan menggunakan metode Certainty Factor yang berbasis dekstop. JURNAL INFORMATIKA UPGRIS VOI. 3, No. 2, (2017).

Qamaruzzaman, \& Sam'ani. (2016). Sistem Pakar Untuk Mendiagnosa Penyakit Mata Pada Manusia Menggunakan Teorema Bayes yang berbasis dekstop. Indonesian Journal on Networking and Security.

Rahmatullah, S., Purnia, D. S., \& Suryanto, A. (2018). Sistem Pakar Untuk Mendiagnosa Penyakit Mata Dengan Metode Forward Chaining yang berbasis web. Repository Nusamandiri.

Ramadhan, P. S. (2018). Sistem Pakar Pendiagnosaan Dermatitis Imun Menggunakan Teorema Bayes. InfoTekJar (Jurnal Nasional Informatika dan Teknologi Jaringan).

Setiawan, W., \& Ratnasari, S. (2014). SISTEM PAKAR DIAGNOSIS PENYAKIT MATA MENGGUNAKAN NAÏVEBAYES CLASSIFIER. Prosiding SEMNASTEK Fakultas Teknik.

Sihotang, H. T., Panggabean, E., \& Zebua, H. (2018). Sistem Pakar Mendiagnosa Penyakit Herpes Zoster Dengan Menggunakan Metode Teorema Bayes yang 
berbasis dekstop. Jurnal mantik Penusa.

Suhendar, D. (2017). Peringatan Hari Penglihatan Sedunia. Bandung: Dinas Kesehatan Provinsi Jawa Barat.

Syahrizal, M., \& Haryati. (2018). Perancangan Aplikasi Sistem Pakar Deteksi Kerusakan Mesin Alat Berat (Beko) Dengan Menerapkan Metode Teorema Bayes yang berbasis dekstop. Jurnal Riset Komputer (JURIKOM), Vol. 5 No. 4.
Umayah, N., Astuti, I. F., \& Maharani, S. (2018). Sistem Pakar Untuk Mendiagnosa Penyakit Pada Tanaman Kakao Menggunakan Metode Teorema Bayes. Prosiding SAKTI (Seminar Ilmu Komputer dan Teknologi Informasi) .

Zoraya. (2018). Kenali Jenis Kelainan Refraksi pada Mata dan Cara Mengatasinya. Jakarta: Jawapos. 